\title{
Inverted Hierarchies on the Shop Floor: The Organisational Layer of Workarounds for Collaboration in the Metal Industry
}

\author{
Frauke Mörike*1뭉 \\ *l Technische Universität Berlin, Institute of Psychology and Ergonomics, \\ Division of Ergonomics, Straße des 17. Juni 135, MAR 3-2, 10557 Berlin, Germany \\ (E-mail:f.moerike@tu-berlin.de)
}

Accepted: 14 September 2021

\begin{abstract}
Workarounds, or practices that deviate from the official pathway to a target, are frequent phenomena in the organisational context. With respect to collaboration, they highlight an area of mismatch between normative versus lived work practices, and therefore depict a relevant research area deeply rooted in computer supported cooperative work (CSCW). Building on the theory of hierarchical opposition by Louis Dumont and empirical data collected through ethnographic research at a company classified as a small- and medium-sized enterprise (SME) in the German metal industry, this paper addresses the emergence of workarounds in collaborative work processes by setting them into the wider organisational context. The organisational layer of analysis reveals that workarounds emerge to cater for inversed information power relations and information asymmetries in the shop floor setting, which require communication to flow against the hierarchical slope between planning and execution functions. By applying an organisational lens to the concept of workarounds, this paper contributes a novel empirical analysis that confirms the value of workarounds as a source of insight into collaborative practices.
\end{abstract}

Keywords: Collaboration, Ethnography, Hierarchical Opposition, Louis Dumont, SME, Workarounds

\section{Introduction}

Workarounds, or deviations from expected work practices, 'remain for the most part surprisingly underinvestigated and [under]theorized' (Pollock 2005). While researchers in computer supported cooperative work (CSCW) and human-computer interaction (HCI) have increasingly devoted attention to the complex and multifaceted manifestations of workarounds, Ejnefjäll and Ågerfalk (2019), in their review of the literature, called for further research on the subject. Workarounds play a decisive role in $\mathrm{CSCW}$ research by furthering the "endeavor to understand the nature and requirements of cooperative work with the objective 
of designing computer-based technologies for cooperative work arrangements' (Schmidt and Bannon 1992, p. 11). They emerge as alternative paths to normative work procedures and underline the 'situated' nature of work (Suchman 1987). Workarounds are therefore directly entangled with long-established concepts within CSCW research, including articulation work (Strauss 1985), workflows (Grinter 2000), and routine/non-routine work (Pentland and Rueter 1994).

The present paper analyses the role of organisational hierarchy in affecting (and even fostering) the emergence of workarounds within collaborative work processes, with particular regard to the metal industry. Applying Louis Dumont's (1980[1966]) theory of inversed power relations, the analysis contributes a novel perspective on workarounds and the situatedness of work at the organisational level, while highlighting the complexity at play in highly collaborative socio-technical work systems. Additionally, the paper provides a set of design recommendations for the management of information flows in the context of workarounds. The application of Dumont's theoretical framework on hierarchical opposition to empirical data from an organisational setting represents a novel contribution to the CSCW literature on workarounds. In particular, the work focuses on three main research questions: (1) Why do workarounds occur, from an organisational perspective? (2) What role does technology (e.g. an Enterprise Resource Planning (ERP) system) play in these situations? and (3) What implications can be derived for CSCW design?

Drawing on empirical data collected through ethnographic research at a company classified as a small- and medium-sized enterprise (SME) ${ }^{1}$ in the German metal industry, the paper garners a multi-level account of everyday work practices in which workarounds are employed to foster cooperation and to react to shifting information asymmetries across functions. Ethnographic methods of data collection have been well established in CSCW research since the early 1990s (Blomberg and Karasti 2013), and a significant proportion of the research on workarounds has employed observational modes of data collection (Ejnefjäll and Ågerfalk 2019).

Dumont's theory of hierarchical opposition (Dumont 1980[1966]) assumes that elements belonging to a whole (e.g. a social system or organisation) are arranged in a hierarchical relationship. This arrangement arises (more or less) independently and in reference to the whole of which each entity is a part. While at first glance Dumont's approach might appear to reinforce stereotypes and dichotomies, his theory in fact challenges the traditional notion of hierarchy as a static construct. In particular, his idea of hierarchical inversion proposes that a hierarchical arrangement can become inversed in certain situations and for a limited amount of time, without fundamentally threatening the dominant hierarchical set-up. Through this analytical lens, this paper presents the results of a study, drawing on ethnographic vignettes to

${ }_{1}$ According to the definition provided by the European Union. 
illustrate the organisational set-up of SteelWorks, Inc. (pseudonym) as characterised by a deep-rooted hierarchical opposition between planning and production functions. This hierarchical arrangement was reinforced by the building architecture, the labels applied to administrative (oben) and production (unten) functions, and the normative and official communication flow in the ERP system, which ran along the hierarchical slope between administrative and production functions.

The results reveal the various workarounds that SteelWorks, Inc. employees applied to channel information flows against this hierarchical slope. During the manufacturing process, production workers held significantly more information on the actual status of manufacturing jobs than the administrative workers, generating temporarily inverted hierarchies. Consequently, workarounds were established to control and effect the upward flow of information-including, in extreme cases, the use of deception. Neither systems nor processes accounted for the inverted hierarchies and information asymmetries: the ERP system represented the dominant hierarchical set-up, but it did not allow for collaborative actions such as communicating feedback from the production team to the engineering office. Thus, the paper highlights that the study of workarounds through an organisational lens can reveal system constraints and configuration needs at the intersection between analogue, digital, and human agents within an organisational system. Workarounds can therefore signify: (1) processes of critical relevance for collaboration, (2) areas of mismatch between information and its intended use, and (3) areas that explicitly require a multi-directional informational flow.

The following section (Sect. 2) grounds the study in the existing CSCW literature on workarounds and related concepts. It then discusses the specific challenges of SMEs as fields of enquiry and opportunity, and introduces Dumont's theory of hierarchical opposition. Section 3 is devoted to the research design and methodological considerations for data collection and analysis, including ethical reflections on ethnographic research in fields dominated by power and dependency relations, such as the work environment. Section 4 presents the results of the ethnographic study, illustrating the organisational setting and the emergence of workarounds in the everyday lived working praxis at the investigated SME. Section 5 discusses the organisational layer of workarounds, in relation to both the challenges that arise from information asymmetries and the potential for workarounds to signify constraints for CSCW design. Finally, Sect. 6 provides concluding remarks.

\section{Related work and theoretical foundations}

\subsection{Coming to terms: Workarounds and related concepts}

The very concept of workarounds connotes essential areas of interest for CSCW research: the possibility of working around something requires the existence of a commonly accepted or normatively prescribed path that may be circumvented 
or deviated from (e.g. a work process and/or technology). Consequently, workarounds relate closely to workflows, articulation work, and routine/non-routine work-topics that have been prominent fixtures on the CSCW research agenda for the past three decades (Schmidt and Bannon 2013). In the 1980s, research on workarounds described these phenomena as the result of a mismatch between systems and work practices; generally-while not exclusively-they were applied to the context of technology (Gasser 1986). More specifically, definitions of workarounds varied from the general 'misfits with the idealized representations of work' (Gerson and Star 1986) to the specific 'nonstandard procedures to compensate for system deficiencies' (Courtright et al. 1988).

Research on workflow systems and the challenges associated with designing systems that support work processes has highlighted the conflict between standardisation and 'flexibilisation', as well as the role of formalism in supporting collaboration (Grinter 2000). Using the example of a configuration management system, Grinter (ibid.) illustrated the supporting qualities of formalised and partially automated systems for software developers. Similarly, other scholars have asserted that plans can be orientation devices (Suchman 1987), guiding maps, or scripts (Schmidt 1997), and that coordination mechanisms may foster cooperative work between actors (Schmidt and Simone 1996).

The literature also underlines the need for greater flexibility to cater for the contingent nature of daily work (Abbott and Sarin 1994); 'improvisation in practice' (Orlikowski 2008, p. 287) when plans don't work out may be an example of such flexibility (Rönkkö et al. 2005). In this context, workarounds may play a decisive role in their capacity to mediate between flexibilisation and standardisation: Gerson and Star (1986) argue that workarounds are the result of articulation work- 'work that gets things back "on track" in the face of the unexpected and modifies action to accommodate unanticipated contingencies' (Star and Strauss 1999, p. 10). Articulation work as 'supra work' —or 'work to make work work' (Schmidt 2002, p. 19) involves workarounds to 'meet local resource constraints, deadlines, configuration limitations, or a mix of technical capacities' (Gerson and Star 1986, p. 366). Both articulation work and workarounds are often invisible in system or process documentation and the end product (ibid.; Dupret 2017; Pallesen and Jacobsen 2018), underlying their nature as work practice phenomena. Both routine and non-routine work are closely related to workarounds, as 'routine aspects of working yield to mechanization, leaving the nonroutine to personal management' (Holt 1988, p. 123). This idea similarly supports the interrelationship between the flexibilisation and the standardisation of work, emphasising adaptability as an essential feature (Hutchins 1991) and the tendency for rapid shifts to occur between what is considered routine versus non-routine work (Holt 1988; Pentland and Rueter 1994).

In relation to normative perspectives on workarounds, Pollock (2005) and others (Beijsterveld and Groenendaal 2016; Gasser 1986) have described 
workarounds as non-standard uses of computing (or uses of alternative, noncomputing paths) to accomplish a task. In other domains, such as healthcare, studies have framed workarounds as temporary work practices (Kobayashi et al. 2005; Zhou et al. 2011), 'clever methods for getting done what the system does not let you do easily' (Ash et al. 2003, p. 195; Vassilakopoulou et al. 2010), means of overcoming the weaknesses of a new system prior to implementation (Bjørn and Boulus-Rødje 2015), means of expressing emotions in formal emergency room documentation (Mentis et al. 2010, 2013), and potential threats to patient safety (Halbesleben et al. 2008).

Conceptual framings of workarounds are quite nuanced. For instance, Strong and Volkoff (2010), focusing on the fit between an organisation and an enterprise, presented workarounds as mismatches between system functionality and work practices. More specifically, these researchers distinguished between two types of mismatches related to workarounds: (1) gaps between the features required by users and the features a system is able to provide (i.e. 'deficiencies') and (2) challenges rooted in the deeper characteristics of a system (i.e. 'impositions'). Other CSCW studies have illustrated how workarounds support the local 'flow of work' in an effort to maintain the prescribed workflow of an international organisation (Avram et al. 2009), and how the interplay between formal organisational structures and informal workarounds can achieve departmental goals of timeliness and safety in the context of aircraft technical support (Lutters and Ackerman 2007).

In contrast to these system-level perspectives, Alter (2014) proposed an actor-centred framework, theorising workarounds as the outcomes of actors' decision-making processes to identify and overcome obstacles in a strictly process-driven approach. Ejnefjäll and Ågerfalk (2019) presented a conceptual understanding of workarounds as alternative paths to goals when the designed paths are blocked. They explicitly incorporated the question of intent, in order to exclude unintentional acts (i.e. mistakes), and further included the precondition of a goal, to distinguish between workarounds and other concepts, such as fraud or sabotage. Some works, connecting workarounds to forms of resistance, control, and disempowerment, have also raised the question of intent (Alvarez 2008; Bain and Taylor 2000; Button et al. 2003; Choudrie and Zamani 2016; Ferneley and Sobreperez 2006; Sia et al. 2002), including those discussing the potential benefits of workarounds (Li et al. 2017; Röder et al. 2014; Safadi and Faraj 2010). The latter are of particular interest for this paper, as their perspectives connect workarounds to wider organisational functioning.

Several works have theorised the deeper causes and consequences of workarounds on the basis of social and cultural science perspectives (Button et al. 2003; Dupret 2017; Pollock 2005; Star and Strauss 1999); this paper seeks to contribute to this body of research. In relation to organisational functioning and the inclusion of the 'social' (Andelfinger 2002), the paper focuses 
explicitly on workarounds in information flows within collaborative processes and the contextual linkages of information in this setting.

\subsection{Workarounds in SMEs}

According to the European Commission, organisations with fewer than 250 employees and an annual turnover of more than 50 million (euro) are classified as SMEs (European Commission 2003). Such firms comprise 99.8\% of all enterprises in the European Union, and represent over $60 \%$ of the workforce (European Commission 2021). Thus, SMEs represent not only a highly relevant research domain, but also one of the most interesting organisational forms, as they are predicted to face the most fundamental changes in the work environment due to digitalisation and the transition to smart factory settings (Lewkowicz and Liron 2019). As SMEs are the backbone of most Western industries, their increasing digitalisation is of utmost relevance (Lindner and Leyh 2019). In this regard, SMEs face specific challenges (Ludwig et al. 2018), as they often lack the funds and resources to foster digitalisation. Consequently, they must rely on the integration of standardised software solutions, which increase the likelihood of workarounds due to their impositions and deficiencies. It is therefore critical that SMEs make correct first-time decisions in their initial steps towards digitalisation. However, only few CSCW studies have focused on workarounds in SMEs (for an exception, see Barata et al. 2015).

This paper examines workarounds in the context of information flows in SMEs, and contributes to closing a gap in the research landscape by positioning workarounds as crucial phenomena. Further, it illustrates how an understanding of workarounds can support decision-making in the process of designing systems for digitalisation, without impacting (or, in the worst case, eliminating) existing successful collaborative practices in SMEs. Finally, it contributes to CSCW research in SMEs more generally (Schnorch et al. 2020).

\subsection{Inverted hierarchies: Dumont's theory of hierarchical opposition}

Modern man is virtually incapable of fully recognizing [hierarchy]. For a start, he simply fails to notice it. If it does force itself on his attention, he tends to eliminate it as an epiphenomenon. Should he finally accept it, as I did, he must still take pains to see it as it really is, without attributing imaginary properties to it. By contrast, all the difficulties vanish if we keep it firmly before our eyes, accustom ourselves to following its outlines and implications, and rediscover the universe in which it operates. (Dumont 1980[1966], p. xlvii)

Inspired by the ideas of Parsons (1977) on the structural affinities between social subsystems and his ethnographic analysis of the Indian caste system, the French anthropologist Louis Dumont developed the theoretical concept of 'hierarchical 
opposition' (Dumont 1980[1966], 2013[1980]), which serves as the theoretical lens for this paper. Hierarchical opposition rests on the assumption that two opposing entities within a whole (i.e. a social system) are arranged in a hierarchical relationship. Applied to organisational theory and an analysis of socio-technical work systems, this implies that the relationships between departments, teams, and functions are not essentially egalitarian, but hierarchical. ${ }^{2}$

Rather than referring to the formal organisation of functions, as represented in an organisational chart, this hierarchical relationship represents a network of values, in terms of the meaning ascribed to organisational entities. In contemporary organisational structures, for instance, there is no hierarchical difference between administrative and production departments, as their managers (and thus their staff) are located on equivalent hierarchical levels. Systems design is typically based on this formal hierarchical structure, often assuming egalitarian work relationships between departments (Mörike 2016, forthcoming). However, as the results of the present study will illustrate, employees perceive a hierarchical relationship, rather than an egalitarian notion of functional value, and this has significant implications for their everyday work praxis. The central benefit of Dumont's approach is that it provides a structurally plausible interpretation of the multi-dimensional peculiarities of workarounds, which can otherwise cause a headache for 'concepts based on static binarity and thus tend to be brushed away' (Houseman 2015).

Dumont holds that hierarchical arrangements occur more or less autonomously. For this reason, he calls on researchers to recognise the hierarchical set-up at the outset of analysis. Importantly, Dumont recognises the hierarchical classification as not isolated, but related to the overall system in which entities are arranged. According to Dumont, the fact that subsystems (i.e. departments, teams) belong to a whole is simultaneously the cause and the consequence of their placement in a hierarchy. This 'assumes that values in relations are never balanced or equivalent [...] but hierarchical when conceived through and defined in relation to the whole' (Kapferer 2011).

Building on the baseline concept of hierarchical opposition, Dumont's second (and, in my opinion, more exciting) idea holds that the established hierarchical set-up is neither stationary nor static. Even more, the hierarchical arrangement can be inversed for a limited time and in specific situations. This occurs without any direct and enduring challenge to the established hierarchy, or even the social system (i.e. the organisation); rather, the inversion occurs on a 'different level':

The reversal is built-in: the moment the second function is defined, it entails the reversal for the situations belonging to it. That is to say, hierarchy is bidimensional, it bears not only on the entities considered but also on the corresponding situations, and this bidimensionality entails the reversal. (Dumont 1980[1966], p. 225)

\footnotetext{
${ }^{2}$ Psychological studies of embodiment in the work context provide support for this idea, showing that employees often perceive the organisational structure as hierarchical (Hurtienne 2017; Schubert 2005).
} 
In the context of process-driven business organisations (as discussed in this paper), one could also speak of 'levels' as processes, through which hierarchical inversions may occur. As this paper will show, a hierarchical inversion was observed at the investigated SME during production processes.

Dumont's approach poses a challenge not only for anthropologists, who rarely describe hierarchy in a favourable light—but also for Western researchers, more generally, as 'hierarchy is not the sort of thing one typically hears Western academics describe in positive terms' (Haynes and Hickel 2016, p. 1). Organisational researchers, in particular, consider hierarchically organised social systems to run against the (primarily Western) ideas of contractual and egalitarian relations that came to the fore in the 1970s (Peacock 2015). Thus, for the CSCW community, Dumont's work might seem to reinforce stereotypes and dichotomies, as it is precisely these hierarchical separations between planning and execution functions ('head' and 'hand', sensu Taylor 2003) that are compensated for by newer organisational models and systems design. But the concept of hierarchical inversion particularly challenges assumptions of static hierarchies, and more recent works in anthropology have explored a variety of ethnographic contexts in which hierarchy is portrayed as a desirable mode of social organisation (Damon 2016; Feuchtwang 2016). Similarly, the findings of this study will show that the assumption of a hierarchical arrangement (i.e. a separation of subsystems) within a lived working praxis may provide a fruitful starting point for an analysis and theorising of workarounds.

While Parsons's work-which inspired Dumont—has been widely cited in HCI and CSCW research (Mueller et al. 2016; Seering et al. 2018; Zacklad 2003), to the best of my knowledge, Dumont's approach has not yet been applied in these fields. This may be because his theoretical outline is difficult to access and can only be found rather implicitly in an appendix to his major work, Homo Hierarchicus (1980[1966]). Mainly, it is only the representatives of his field of social anthropology who have attempted to apply his ideas or provide practice-oriented interpretations (e.g. Hage et al. 1995; Mosko 1994; Sprenger 2006).

\section{Method}

Based on the above considerations, this paper contributes an empirical analysis of the impact of hierarchical structure on workarounds in an SME, particularly with respect to actors' collaborative work. To approach a wider understanding of workarounds in lived everyday working praxis, an ethnographic research design was applied, as detailed in this section, in terms of data collection (Sect. 3.1), data analysis (Sect. 3.2), and ethical reflections (Sect. 3.3). 


\subsection{Ethnographic research design}

Ethnography, which was originally developed for research desiderata in the cultural and social sciences, has been part of the methodological toolbox within CSCW research since the 1990s (Blomberg and Karasti 2013; Iqbal et al. 2005; Randall et al. 2005). Ethnographic research in the workplace plays 'an essential and proactive role' (Schmidt 2016, p. 357) and denotes 'a key strategic goal' (Schmidt and Bannon 2013, p. 351) of the CSCW research programme. Indeed, numerous studies have demonstrated that ethnography provides highly relevant insights for both CSCW (e.g. Heath and Luff 1992; Karasti and Blomberg 2018) and HCI (Foley et al. 2019; Fox et al. 2019). In particular, the strength of ethnography rests in its mode of in situ data collection with an open perspective, whereby work practices and collaboration phenomena are observed in their natural context. Ethnography requires researchers to immerse themselves in the group or social setting under investigation with more or less active participation and/ or observation (Madden 2017). This enables them to capture detailed first-hand knowledge of informants' everyday routines and their opinions on these routines, and to gain insight into the often-unarticulated networks of relationships. Through this method, researchers may gain a deeper understanding of the organisation through the perspective of the accompanied workers and their paths, connections, and strategies of working (ibid.). Ethnographic fieldwork includes not only sitting next to workers at their desks or equipment, but also following them to spontaneous catch-ups with colleagues and joining them at meetings and coffee breaks. Throughout the day, researchers may ask the occasional question to understand the context of an activity or conversation and to determine a direct reaction to a situation (McDonald 2005). In doing so, they may connect the behaviour or situation to a comment or opinion, and thereby gain insight into the practical context. Thus, the idea of ethnography is not to 'determine the truth, but to reveal the multiple truths apparent in others' lives' (Emerson et al. 2011).

The data for this study was collected over a period of 2 weeks in September 2018 in an SME in the German metal industry with approximately 130 employees. To protect anonymity, the SME is referred to here under the pseudonym SteelWorks, Inc. During the data collection phase, I accompanied 10 employees throughout their workday, beginning with the early morning (i.e. 6:00 am) shift and progressing through to the close of business. To gain an understanding of the relevant collaborative processes that were central to the organisation's value chain and potential workarounds, I accompanied employees from a broad range of functions and hierarchical levels, from product engineers to purchasers, production planners to shop floor replenishers, and administrative assistants to members of the plant's management team. Employees were observed along several steps in the metal working process to the final product assembly and distribution. Half of my days were spent with employees in the production hall, while the other half were spent with administrative staff. 
Towards the end of each workday, I conducted a semi-structured interview with the employee I accompanied that day, with each interview falling in the range of 25-45 min. The interview data were enriched by dozens of spontaneous, informal conversations in the smokers' corner, at the lunch tables and coffee machine, and in the hallways_-both with colleagues I accompanied and with other employees. These 'informal' interviews were documented as memory protocols in the field notes.

This paper draws on the data collected during my fieldwork, consisting of over $90 \mathrm{~h}$ of shadowing data and $5 \mathrm{~h}$ of recorded and manually transcribed interview material. Furthermore, 6 months after the fieldwork was completed, a feedback meeting was held at the SteelWorks, Inc. premises and all employees who participated in the study were invited to attend, along with the management team and representatives of the workers' council. At that meeting, I presented some of my preliminary results, after pointing out that my research explicitly sought to avoid judging or criticising the lived working practice. I emphasised that I was highly interested in the extent to which the attendees saw themselves represented in my presentation. This stimulated a lively discussion about the organisational set-up and the workarounds I observed, as well as their implications for collaborative processes. The session served as both a validation mechanism for the interim findings of the study as well as an opportunity to clarify potential misunderstandings from my side. Therefore, it was also documented and integrated into the analysis (Figure 1).

\subsection{Data analysis}

Data collected through workday shadowing took the form of hand-written jottings. At the end of each day, these were transformed into consolidated field notes spanning 6-8 pages and uploaded-together with the interview transcripts - into a software tool for qualitative data analysis (MaxQDA). To analyse the data, I employed an iterative analysis process inspired by (but not congruent to) grounded theory methodology (Emerson et al. 2011; Glaser and Strauss 1967). This involved a close reading of all field notes as a complete corpus, which allowed me to re-experience and re-examine the 2 weeks of field work. Following this, I applied a first round of open coding to the field notes, whereby

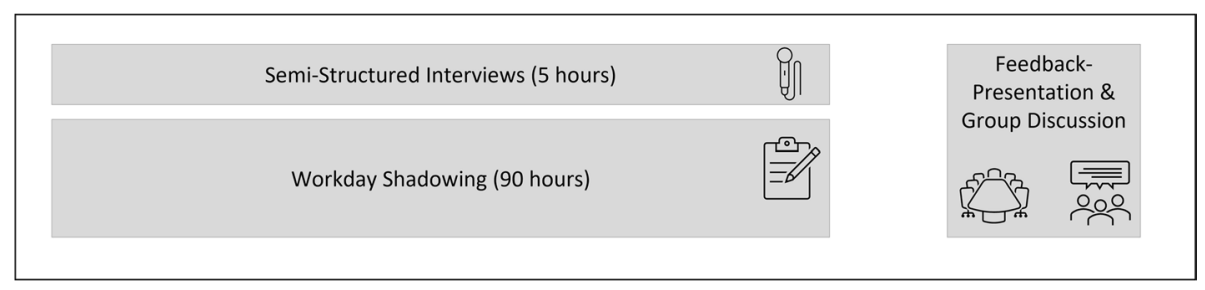

Figure 1. Data Collection Methods. 
I created a set of codes and descriptive initial memos, which I discussed with fellow researchers in my department. This generated a set of topics identified as relevant, which I applied to several iterations of focused coding of the field notes and interview transcripts. At this stage, I delivered my feedback presentation at SteelWorks, Inc., which explicitly affirmed the relevance of the code activities/workarounds to bridge organisational divides and generated further feedback on several other examples of workarounds that the attendees employed. Furthermore, the topic of generation change, which frequently arose in conversations during the fieldwork, was clarified, insofar as the attendees saw it as a key concern pertaining to knowledge retention within the organisation, rather than a topic of direct relevance to collaboration within the organisation.

Input from the feedback presentation, in the form of a detailed protocol, was incorporated into the data set, and the process was repeated, iteratively moving from open coding to focused coding and from initial memos to integrative memos that linked analytic schemes and categories. The MaxQDA tool allowed for different combinations of the main codes and subcodes, which greatly facilitated my interpretation of the data. During the analysis, codes, memos, and emblematic vignettes were discussed iteratively with fellow researchers. The final parent codes that emerged from the iterative process were divides, referring to formal/informal/physical/digital gaps in the organisation, the activities/workarounds employed to bridge these divides, perceptions/ascriptions of hierarchy, tasks associated with collaboration and boundary management, and communication channels used to engage in the boundary work. Every main code contained several subcodes, representing different dimensions of the main code.

\subsection{Ethical considerations}

Access to SteelWorks, Inc. was initially gained through the factory manager, who forwarded my request for access to representatives of the organisation's workers' council. Based on the representatives' input, an employee information sheet about the study was created and posted on the main bulletin boards throughout the SteelWorks, Inc. facility, a few weeks prior to the start of data collection. Employees who were interested in participating were invited to contact a member of the workers' council, and any employees who preferred not to interact with me during my research were encouraged to flag their concerns, to ensure that they would not be observed when their colleagues were being shadowed. A single representative of the workers' council served as the primary contact person and moderator for the study. Prior to the data collection, this representative organised basic training for me on safety in the shop floor environment and introduced me to the employees I would be shadowing. Before the study began, each employee who agreed to participate was informed again about the research, signed the corresponding informed consent (IC) form, and verbally approved the audio-recording and transcription of their interview. In the event that an employee objected to 
the audio-recording, their interview was documented in written notes. All nonparticipating employees were informed about the study through notes posted on office bulletin boards and invited to become lateral participants by interacting with the shadowed employees. In accordance with the scale of situation-adjusted privacy expectations (Heibges et al. 2019), lateral participants were not asked to sign an IC form, but were verbally and through the bulletin boards informed about the research and the nature of the collected data. The study design was filed with the institutional review board of my university and was awarded ethical clearance prior to the data collection. The results presented in Sect. 4 follow the overarching ethical command to ensure the anonymity of informants. Where pseudonymisation and anonymisation strategies were not sufficient to mask the identity of an informant, the relevant data were withheld from the reporting.

In my first moments and days in the field, I occupied myself with sounding the atmosphere within the organisation in order to position myself as unobtrusively as possible as a female researcher in the male-dominated work setting. Incidentally or not, on my first day, I was given the opportunity to accompany a female colleague, and this allowed me to closely observe her modes of interaction with colleagues. Equipped with steel-toed boots, protective glasses, and clothes that could withstand the spray of machine oil, I framed my role on the shop floor as an interested novice in the field of metal-working. This seemed to fit with the context, as the attitude towards me, as a female researcher, ranged from neutral to curious/positive. The time I spent in the smokers' corner likely also contributed to bridging some of the apparent differences between me and the employees, and enabled me to build a rapport. My presence seemed to be a welcome change to working life at the plant, which was otherwise characterised by a limited set of iterative routines. Over the 2 weeks of fieldwork, these impressions of me seemed to persist. I can imagine, however, that a longer period of fieldwork (e.g. several months) would have required me to position myself within the group's informal hierarchy, thereby making our differences more salient. An unexpected gap arose from the fact that I came from Berlin-representing not only the country's capital, but also the largest city in Germany. Employees often voiced their surprise that someone from Berlin would be interested in visiting a company in the 'rural province'.

\section{Results}

In the following, the results are presented in a stepwise fashion, zooming in on the details of SteelWorks, Inc. working practices. Beginning with a description of the architectural setting of the facilities, Sect. 4.1 addresses how the physical division of the offices is mirrored in the perceived hierarchical relations between the administrative and production departments. Building on this context, 
Sect. 4.2 describes the standard communication flow along the hierarchical slope from administrative to production functions; Sect. 4.3 presents how the employees applied workarounds to foster information flows against this hierarchical slope; and Sect. 4.4 further explores how employees used these workarounds to control and effect an information flow from production to planning functions. Finally, Sect. 4.5 portrays how deception was used as an extreme form of workaround to foster an upstream flow of information, and concludes with a discussion of hierarchical inversion and its consequences for systems design.

\subsection{Oben/unten: A setting of division and hierarchical opposition}

The physical set-up of the SteelWorks, Inc. plant is characterised by an architectural division between the production hall and the administrative offices (Figure 2). The boundary between these areas is clearly demarcated by the heavy steel doors to the production hall, which feature signs indicating that security glasses and steel-toed boots are required beyond that point; in contrast, no specialised gear is required for accessing the office area. Thus, the production hall is labelled as a potentially hazardous area, within which employees require protection.

All labour that is directly related to the production of goods is carried out on the ground floor of a large production hall at the rear of the SteelWorks, Inc. facility. The front side of the building, which is attached to the production hall, hosts the administrative offices, spanning three levels. Plant management functions are located on the first level. Here, the operational administrators and the production manager work in a central open-plan office space. The second level hosts the product engineering team. This space is almost exotic, with international and highly academically qualified staff. It is positioned at the most distanced point from the turning lathes in the production hall.

While there are several routes from the office space to the production hall, the latter is most frequently entered via the open-plan office. From the office, with its noise curbing carpet, a hallway with linoleum flooring leads to the heavy steel

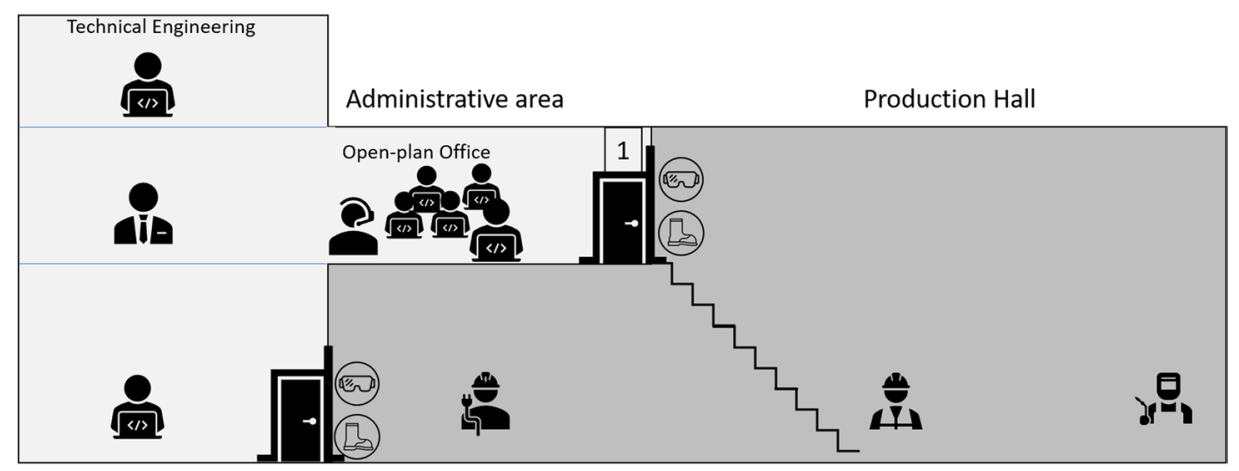

Figure 2. Overview of the Research Setting. 
door with large blue signs indicating the requirement for protective gear. Thus, the linoleum hallway represents a transition space, emphasising the need for a managed boundary between the two organisational areas.

Upon opening the heavy steel door, which requires a strong pull, one must descend a steel staircase to progress into the production hall. From the top of the staircase, one can view the entire machine park, featuring lathe and milling machines and their operators, wearing boiler suits. The atmosphere is strikingly different from the office space: the air is filled with metallic noise, there is a distinct smell of machine oil, and colour-coded lines on the floor mark walkways and parking areas. Thus, entering the production hall requires not only safety gear, but also knowledge of the basic rules of conduct to manoeuvre safely in the space, such as the standard right of way for the forklift truck or the taboo against touching the razor-sharp steel chippings without suitable protection gloves.

The physical divide between the production and administrative functions finds its first verbal representation in the very distinction between 'the production' and 'the administration'. However, the second frequently-used dichotomy to differentiate between these modes is captured in the German terms oben ('upstairs' or 'above') and unten ('downstairs' or 'below'). The usage of these terms is highly contextual: oben can refer to the open-plan office in general, specific teams or individuals in the open-plan office, the product engineering department, the management team, or simply colleagues occupying a superior position in the hierarchy. More figuratively, oben can be used as a synonym for a lack of awareness and understanding of the reality of the organisation's grounding work:

At around 8:30 am, my shadowing partner for the day - a production worker - and I stood at the coffee machine in the production hall when the plant manager and his managing team walked in a group across the main walkway of the production hall to start their daily update enquiry round across all teams relevant for production. My shadowing partner followed the small group (which he later labelled as 'the delegation') with a gaze, before turning to the coffee selection. While nesting into the coin slot of the coffee machine, he gave me a sideways glance and commented that he wasn't sure of the usefulness of this activity [the daily update walk], as, in his opinion, 'they' were not aware of 'what is really going on', by which he meant the real issues faced when handling the turning lathes day in and day out. They simply would have a view 'from above' on the processes. (Field notes)

While the above comment, which was delivered with an unmistakably critical undertone, illustrates the organisational divide, it also affirms the existence of a hierarchical structure. The production worker denied that those from 'above' were fully aware of what was going on 'down here', but at the same time acknowledged the need for functions that looked down on the production processes 'from 
above'. This is relevant, as it shows that the production worker understood both positions, oben/unten, as parts of a whole, in the sense of Dumont's hierarchical opposition. Another relevant issue is foreshadowed by the worker's statement that the upper management team was not aware of 'what is really going on', suggesting that 'what is really going on' (i.e. unten) played an important role-and potentially a more important role than oben-in the work processes. This is of particular importance for the practice of workarounds, as discussed in Sect. 4.5.

The physical set-up of the SteelWorks, Inc. building is mirrored in not only the division of administrative versus production functions, but also the hierarchical relationship between oben and unten (Figure 3).

This idea is reinforced by several interactional and structural examples from my research data.

When I casually talked with a member of the open-plan office about my research plan and mentioned that I would be accompanying a colleague at a turning mill the next day, the response was: 'Are you sure you want to accompany him for a day? I can absolutely not imagine what you would like to do there for a full day - a couple of hours should be enough.' We bumped into each other again a few days later and he stated that he still couldn't understand what I might have found interesting enough at the turning mills to observe over a full workday. (Field notes)

As the 'worthiness' of my observation was never questioned when I accompanied employees in administrative functions, there was an implication that jobs in the production area were of lesser value. In line with this, the telephone lists displayed on several desks listed only administrative employees by name. In contrast, workers in the production hall had neither an assigned telephone number nor a company email address. On the telephone lists, they were merely listed via function (i.e. 'incoming goods management'). Finally, to underline this division

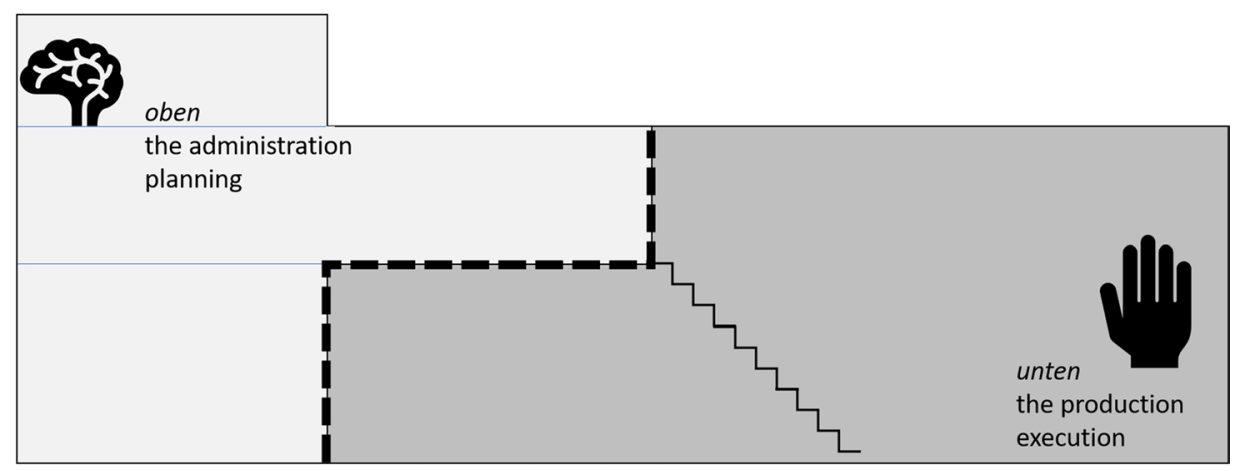

Figure 3. Hierarchical Opposition at SteelWorks, Inc. 
between 'the head' and 'the hand' (i.e. mental planning versus manual execution, as depicted by Taylor), the engineering team was referred to as the 'brain of the company', as 'they have the most information about products and everything new comes from here'. At SteelWorks, Inc., this metaphor even applied to the physical structure of the plant, as the engineering team was located in the uppermost area of the building.

One of the production workers related this structural divide to a potentially conflictual consequence for collaboration:

Collaboration? Hmm, from my experience, as soon as there is a door between two sides, there is also a battle. (Interview, production worker)

The above examples suggest that the structural division of the SteelWorks, Inc. building was met by a corresponding verbal representation of a hierarchical relationship between the administrative and production functions (i.e. planning and execution). This organisational divide into the oben/unten dichotomy stimulated a discussion during my feedback presentation (which occurred 6 months after my fieldwork at SteelWorks, Inc.) about other descriptions used for the administrative and production functions. For instance, as the administrative area at Steelworks, Inc. is closer to the street and entrance hall, some of the attendees claimed that they referred to administrative workers as 'those at the front' and production hall workers as those 'at the back'. During my fieldwork, I did not come across these alternative labels in practice, and thus I cannot comment on the context in which they might have been used. Nonetheless, this discussion affirmed that administrative and execution functions were labelled on the basis of the architectural setting, with its clear hierarchical connotations. Clearly, this organisational set-up comprised the relevant context for the communication flows operating within SteelWorks, Inc. and the workarounds associated with these flows.

\subsection{Brain to hand: Downstream communication and the digital/analogue divide}

The results presented in this section illustrate the established information flows concerning boundary management between the administrative and production functions at SteelWorks, Inc. In particular, they demonstrate three relevant findings for the emergence of workarounds: (1) the established communication flow runs downstream along the hierarchical slope, from planning to production functions; (2) the transition point between the administrative and production functions delineates a boundary between digital and analogue information, which renders the manufacturing processes on the shop floor relatively opaque; and (3) the backflow of information from the production hall to the administrative offices is less clearly established, and requires workarounds (Sect. 4.3). As SteelWorks, Inc.'s ERP system does not represent the organisation's full suite of technology, my initial approach in the fieldwork was to focus more broadly 
on digital technology. However, the data quickly highlighted that the ERP system, with its process-oriented and functions-encompassing capacity, should be my primary focus.

At SteelWorks, Inc., the technical engineering team is responsible for the construction of all products. For this purpose, they employ digital tools, including computer-aided design (CAD) software. The main outputs of these tools are the technical drawings for each product. These are stored on a central server and linked to the product master data in the ERP system. A key function of the information flow for product manufacturing is order preparation. The order preparation team acts as a link between the construction and production teams, ensuring that ideas from the mechanical engineers are implemented in the manufacturing process. Thus, these employees operate on a long-term planning level, and are responsible for determining the machine with which certain products will be manufactured. On a daily basis, they are responsible for production scheduling-determining which steps of an order should be manufactured, and at which time, at what machine, and (of greatest relevance to this paper) by which worker.

When an order arrives at SteelWorks, Inc., via fax or email, the order preparation department inputs it into the ERP system, from which it can be accessed (after several review steps) by the sales and procurement teams. In parallel, a paper file copy of the order arrives in a physical inbox labelled 'new orders', which triggers the order preparation team to incorporate it into the operational planning. Following this, a production order is generated and, if the order is scheduled to be manufactured within the next 3 weeks, a print-out of the order and the corresponding bill of materials is attached to the folder, before it is temporarily stored in a cabinet. Every 2 to 3 days, the paper orders are finalised as work orders for individual components or manufacturing steps, and supplemented with print-outs of any technical drawings required. These orders are manually carried downstairs to the central Kanban board in the production hall. From there, each work order moves along the individual steps in the production process; this means that the paper file is sequentially allocated (by the order preparation team) to individual to-do boards for different machines, with the respective steel objects following along with it.

When the machine operator starts his workday, ${ }^{3}$ he goes to his work order board, where the orders are sorted into plastic trays labelled 'Prio 1' to 'Prio 5', indicating the sequence of activity. From there, he fetches the file with the work order, takes the print-out with the technical drawing and attaches it with magnets to the iron door of his turning machine. He then mounts the first unmachined part onto the turning mill and starts to programme the required radii, angles, turning speeds, and tools on the control panel of the machine, according to the technical drawing. When the order is finished (depending on the order size and complexity, this might

\footnotetext{
${ }^{3}$ At the time of my fieldwork, aside from a few women in the final product assembly area, the workers in the production hall were exclusively men.
} 
take up to several hours), the workers indicate this on a terminal with a touchscreen, where they log the set-up time required, the actual production time, and the number of parts completed. As soon as they confirm their entries, the information runs back into the ERP system and the workers proceed to the next order.

Although the ERP system plays a managing role in this process, the interplay between digital and analogue modes of communication is particularly striking. The process steps carried out by administrative staff are recorded on both physical paper and in digital ERP records. However, as soon as the orders are prepared for manufacturing, only the paper representations enter the production process.

In the past, we printed all orders as soon as we checked them [in the ERP system]. Now, we only do this for the next 3 weeks. So if there is a change before the orders go downstairs, you can now simply delete it in the system and you don't have to go down anymore to find the work orders somewhere. (Interview, order preparation team member)

This quotation, together with observations of order preparation team members walking across the shop floor to track down and update or remove the paper copy of a work order, affirms the break in the information flow. As soon as orders are transformed into analogue representations and passed through the steel door, down the stairs, and into the production area, they are detached from and untraceable in the ERP system. This digital/analogue divide occurs at the transition point between the administrative and production teams, and hence the boundary between the planning and execution functions-between oben and unten. The next digital traction point occurs when a worker logs a manufacturing job in a terminal, which turns the information flow back from production to administration.

The downstream communication flow from the verified origin of an order in the ERP system to its executable counterpart in the production hall seems more clearly defined and established than the counter-directional flow. In SteelWorks, Inc., the information flow is primarily designed as unidirectional, running down the hierarchical slope from planning to execution and mirroring the architectural and organisational hierarchy of 'brain' over 'hand', oben over unten. Furthermore, the data illustrate that the official back-flow of information from the shop floor up the iron staircase is narrowly designed, and dependent on production workers managing the transition from the analogue manufacturing job printout to a digital representation within an entry terminal. The interdependencies between the work done by the engineers, the order preparation team, and the production workers, and the consequences of the digital/analogue divide, become salient in the workarounds employed to bridge this divide. The following section focuses on the workarounds associated with information management at the interface between planning and production, as the designed back-flow of information via the ERP system does not facilitate cross-functional cooperation. 


\subsection{Workarounds to manage the staircase}

During the morning's cigarette break I stood next to a colleague from the production team. He wanted to know who I was accompanying that day, then asked me: 'So you're with the order preparation team today? Do you already know what they are doing?'

I answered: 'Production planning?'

Production worker: 'Yes, planning - that's the right keyword - and they do this far from reality.' (Field notes)

The above exchange illustrates the disconnect discussed in previous sections, whereby the shop floor was understood as 'the reality' and the administrative functions (hyperbolically) as an area of fantasy. Shortly following this conversation, this idea manifested in lived working practice: my shadowing partner from the order preparation team sat in front of his screen and remarked that 'the reality' did not always match the ERP system, and a significant proportion of his workday was invested in approximating the system's numbers to more closely accommodate what he saw as 'the facts' from the shop floor.

He spent the morning tracking down a manufacturing job that was originally for 20 pieces, but later increased to 40 . However, only 20 pieces were booked into the system and logged in the terminal next to the turning lathe. He discussed the incident with his teammate, who was sure that the 40 pieces had been manufactured, as he remembered that he had directly told the production worker to increase the job to 40 pieces. Looking at the computer screen in the open-plan office, it was impossible for either to draw conclusions about what to enter. So my shadowee went downstairs to the production area and spoke to his colleague at the respective machine, who assured him that he had produced 40 pieces. Back upstairs at his desk, my shadowee entered the quantity ' 40 ' into the computer system and commented to me with a sigh: 'Now I have to trust the statement of the production guy or do a lot of inquiry work.' When I asked what he meant, he explained that he would have to search for the parts across the entire production hall, but some might have already been taken to assemble new products. Hence, his decision was to overwrite the official booking of 20 pieces to 40 and to close the process. (Field notes)

Throughout the day, my shadowee walked up and down the staircase and subsequently corrected/updated data in the ERP system, seeking alignment between the manufacturing praxis on the shop floor and its digital representation. Instead of relying on the digital information flow from the terminals at the turning lathes into the ERP system, as intended by the process design, the order preparation worker employed several workarounds. As illustrated by the example above, the main workaround was to engage in face-to-face communication with colleagues 
on the shop floor to collect the relevant information, and to literally carry this information up the stairs to the open-plan office.

A second established workaround to catalyse information flows against the hierarchical slope was to display yellow cards (similar to those used by football referees) to signal and prioritise. The order preparation team displayed yellow cards to trigger an information flow from the production team upwards to the mechanical engineering team. Typically, this occurred when a technical drawing was reported as incorrect or incomplete by a machine operator. In this event, issues with the drawing would be documented on a Post-it note on the printed technical drawing and put on a cabinet in the open-plan office. Once production planners received these print-outs (often several hours later), they would document them digitally via an email response. However, whenever an issue was considered urgent, the yellow card would be put on a carton that was highly visible across the office floor and would be quickly noticed by an assistant in the mechanical engineering department. The assistant would then deliver the file to one of the mechanical engineers on the second floor, for further action (Figure 4).

This practice illustrates that the processing of such information was deemed important enough by the organisation's employees to establish a workaround

Figure 4. The Yellow Card, Indicating the Need for Urgent Feedback from the Production Hall.

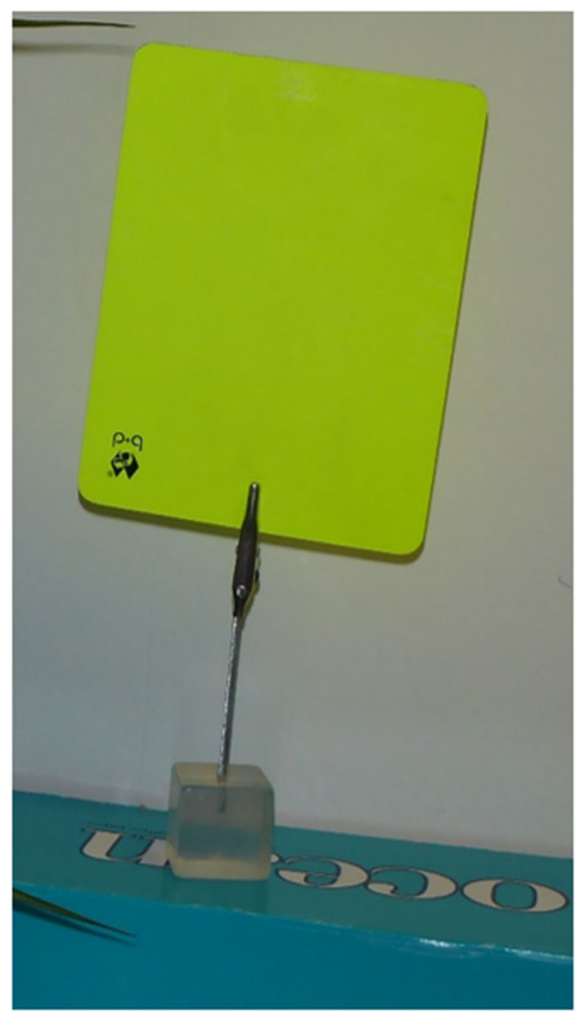


process requiring an explicit manifestation (through the yellow card as an artefact) to facilitate an information flow from the manufacturing hand to the manufacturing brain. It is apparent that the designed information flow (at the intersection between the digitally managed planning process and the analogue work orders) ran significantly more smoothly down the staircase than in the opposite direction, as it required several workarounds to flow up the hierarchical slopeliterally upstairs towards the administrative functions. The following section sheds further light on situations in which workarounds were employed to control information flows.

\subsection{Workarounds to maintain opacity}

It was early morning, shortly after 6:00 am. The shift had just started. The production hall was already fully lit and in busy operation mode, while most of the administrative offices were gloomy and vacant. I was accompanying a production worker. After milling the first items, he paused for a moment and his gaze turned upwards towards a row of windows at the other end of the hall. They had caught his attention because the lighting there had just turned from a dimmed standby level to full brightness. The windows belonged to the open-plan office area, and my shadowee reacted to the lighting stimulus with a grumbling frown, before continuing to sort the required tools and materials for the next work task. 'As one can see, the workday over there has also started in this moment', I commented, in an attempt to grasp the motivation for his reaction.

He stopped again and looked at me: 'Yes, but that's about all you can see from here on what's happening. But the other way round, everyone up there - they can see everything we do here. Like, who's working what, and you never know who is watching you.' (Field notes)

The above vignette connects the structure of the SteelWorks, Inc. building to Bentham's 'panopticon'- a macro-ergonomic design for prisons and production plants in the 1880s, which allowed for the supervision of many by only a few in control. Michel Foucault later developed Bentham's design into his concept of 'panopticism' (Foucault 1995), which he used as a metaphor for the increasingly individually embodied power relations of modernity, with the constant threat of observation by supervisors. Foucault held that, as subjects under surveillance can never be sure when they are being observed, they adjust their behaviour in accordance with the given norms. Researchers have applied Foucault's ideas in the context of video surveillance in public spaces (Foth et al. 2014; Rothmann 2017; Veeraraghavan 2013) and HCI researchers have applied them in the context of health tracking devices (Light and Wright 2009), ERP systems (Sia et al. 2002), location-based services in families (Boesen et al. 2010), and negotiations of control and resistance in the workplace (Bain and Taylor 2000). 
In the above scene, the production worker comments that the architectural structure of the building allows the employees in the open-plan office to observe the entire production hall without being noticed by the production workers. $\mathrm{He}$ voices dissatisfaction with this threat of constant surveillance, in the sense of Foucault's panopticism. However, his suspicions do not meet with the reality of the lived praxis in the open-plan office, as fewer than a handful of the employees in that office have their desks in positions overlooking the windows to the production hall; others have to move in an unusual way across the floor and enter other teams' working spaces to achieve this vantage point. In my fieldwork, I only observed such behaviour when employees were looking for a member of their own team in the production hall; not to check on the production workers.

Nonetheless, the production worker's sentiments are relevant to the workarounds used to manage the shop floor and the data in the ERP system: the production workers' suspicion and perception of being under permanent surveillance may have bled into a general suspicion of the company's digital systems, including the production hall terminals used to log the time required for machine setup and manufacturing. Contrary to Foucault's argument-that, in a panopticon environment, rules and behavioural norms are internalised and adhered to without explicit control- the SteelWorks, Inc. production workers employed workarounds in their work logging, perhaps in an effort to maintain a protective veil over the shop floor reality.

The practiced workarounds included either logging the total duration of a manufacturing job without indicating a specific duration for the set-up time, or occasionally 'forgetting' to log time altogether. Such instances were often contextualised with the comment that the standard set-up time indicated for a job was not representative, as it was not realistic to expect an average or inexperienced worker to perform the task in that timeframe. Production workers also perceived a deep lack of understanding of the nature of their work, as the following quote illustrates:

Some people from the administration seem to think that I simply throw together some raw materials and tools, shake them once, and everything is ready. I always tell them that there is no 'just quickly' because everything always takes a while [to manufacture], no matter what. (Field notes)

Connected with these workarounds to protect the actual work situation on the shop floor were workarounds used to shape the sequence of manufacturing jobs. Individual strategies to arrange manufacturing jobs were important to the production workers, who felt undervalued in their expertise with respect to clustering or sequencing jobs in the most efficient way. As they had no influence on the overall planning and scheduling of manufacturing jobs, they employed workarounds by inspecting the paper files for jobs scheduled in the coming days and 
prioritising or postponing certain jobs, irrespective of the priority folders they had been sorted into by the production preparation team.

We were standing in front of the to-do board and the production worker was selecting the jobs for the day. He pointed at one file and commented: 'I'll leave this [job] sitting here until someone shows interest. Before that, I won't do anything. It's not suitable for this machine anyway. I would never attempt to manufacture such a job on it.' (Field notes)

The consequence of such workarounds was similar to that of the workarounds practised by the production planning team in their efforts to connect reality with the ERP system, as described in the previous section. While the workarounds discussed here aimed at maintaining the opacity of the production process, the following section reports an incident in which opacity was used to catalyse an upstream information flow when the material object of the yellow card was considered too weak to facilitate this process.

\subsection{Deception as a workaround to foster upstream information flows}

Late afternoon at the turning lathe: A member of the production planning team approached the production worker I accompanied that day, one of the lathe operators, with a highly urgent manufacturing job that needed to be done immediately, as the client was calling every day to enquire about the order status. After a short discussion, they agreed that the production worker would take care of the job the following morning.

Next morning, 7:30 am: Upon entering the production hall, I met the production planner and casually asked him about the status of the urgent job from the previous day. He took a deep breath and told me that the production worker had started to work on the job that morning, but there was a significant error in the technical drawing and hence he had machined the part incorrectly and it was unusable for further processing. He now had to organise for another raw part to be produced as quickly as possible and for the drawing to be corrected, so they could start anew with the process. [...] He needed to organise that immediately, since the customer was putting a lot of pressure on the company. In seemingly high alert, he rushed up the staircase to the open-plan office.

A few minutes later, I approached the production worker and asked him about the urgent job, as I had learned from the production planner that it had to be re-done $[\ldots]$ The man took a quick glance around the hall and told me in a low voice with a broad grin on his face that this was not the case. He had noticed the error on the drawing early enough to exclude the critical 
areas from machining. But, together with his team, they had taken the decision to come up with the story that the part would have to be manufactured anew. He said: 'If I had turned my head off this morning and just worked according to the drawing, it would have happened like that. Then inevitably a new part would have had to be made.' He added: 'We underlings also have to find a way to show that we're able to think and use our mind down here, too!'

Same day, 9:30 am: The story about the ill-manufactured part was maintained for over 2 hours. But when the increasingly stressed-out production planner checked again with him to enquire whether a raw part with a different alloy might be an option, the production worker finally terminated the drama and dissolved the matter. The production planner registered the news expressionlessly and later commented to me that they had simply played a joke on him. At that moment, the incident was already brought to the prioritised attention of the mechanical engineers and the plant manager. (Field notes)

The event described above did not lead to any negative consequences for the production worker. However, during my next observation in the engineering office and at the plant managers meeting, different options to ensure that the correct technical drawings were attached to manufacturing jobs were discussed. Without this incident, such a discussion would have likely never been raised. Thus, this vignette illustrates how deception could function as an extreme form of workaround to foster the flow of information against the hierarchical slope. By yarning a catastrophe tale based on an incorrect technical drawing for a manufacturing job, the workers instigated sufficient momentum to force their feedback immediately on the mechanical engineering team and, in parallel, the plant manager, situated at the highest hierarchical level. This workaround can be understood as an intensified version of the yellow card workaround, which was similarly used to facilitate an information flow in this direction. The example underlines the perceived relevance of back-loop information flows from the production area to the administrative functions - and at the same time an unmet need in systems and/or process design.

The incident furthermore poignantly shows that the workers were fully aware of their information advantage about the 'reality' on the shop floor, and the power granted to them by the opacity they maintained over the production hall. The production worker and his teammates knew that they could successfully employ the catastrophe tale, as details about the actual status of the part's manufacture were only known to them, and not to members of the administrative functions. At that moment, the production team held significantly more relevant information than their administrative colleagues, and they used this information advantage to trigger a flow of feedback about the insufficient quality of the technical drawings. 
It is notable that the production worker was the one who decided to dissolve the situation. For a short moment, he turned the established hierarchy upsidedown and highlighted the knowledge advantage of the production workers for manufacturing processes. His remark-'We're able to think down here, too!'vehemently challenged the idea of the hierarchical opposition between the thinking brain and the executing hand, demonstrating that the execution function could operate beyond the task of blindly fulfilling a manufacturing job. The goal of this deceptive workaround was to ensure that feedback would reach recipients at the upper levels in the hierarchy. Hence, the production worker did not question the organisational structure and value system as such, but he merely highlighted the fact that the information expertise lay with the production team during the manufacturing process, and that the dependencies were inversed in this context. This is exactly equivalent to Dumont's understanding of hierarchical inversion: at certain points in the SteelWorks, Inc. value chain (namely the execution of manufacturing jobs), the dominant hierarchical structure was inversed. In these moments, the production workers held more information power. This highlights that, while a hierarchical set-up may be neither stationary nor static-designed processes and information systems are. Based on these results, I argue for the inclusion of an organisational layer of analysis in any examination of workarounds, takes such circumstances into consideration.

\section{Discussion: The organisational layer of workarounds}

The present results provide deep insight into the organisational layer of workarounds within collaborative work processes in an SME. The hierarchical setup of an organisation was shown to fundamentally influence the emergence of workarounds, which were employed to either foster the opacity between planning and execution functions, or, reversely, to catalyse an information flow against the hierarchical slope, from the production hall up to the administrative area. Thus, this paper makes an original contribution to the CSCW literature, representing an organisational analysis of how the hierarchal structure of a company in the metal industry affected and/or created workarounds within collaborative work across functions (i.e. planning and production). Workarounds were contextualised within the wider realms of organisational functioning, and the results underlined the need for further theorising research in this area (Ejnefjäll and Ågerfalk 2019). Drawing on Dumont's concept of hierarchical inversion, workarounds were understood as 'phenomenologically situated phenomena' (Harrison et al. 2007) and used to illustrate interdependencies within work settings, with fundamental relevance for CSCW design (Hughes et al. 2000). Furthermore, the application of Dumont's theory situated workarounds in a context of wider organisational functioning, extending beyond a generalised indication of the 'social' (Andelfinger 2002). The study therefore reflected and furthered the CSCW research focus of 
'understanding and supporting communication and cooperation among people, rather than automating specific tasks.' (Gerson 2008, p. 193).

\subsection{Inversed information asymmetry relations and the role of technology}

The present findings revealed an organisational set-up with a deep-rooted hierarchical opposition between administrative and production functions, in accordance with Dumont's theory (expressed in the metaphor of oben versus unten). In correspondence with this idea, the information flow at SteelWorks, Inc. was designed to flow from the conceptual planning departments at the top to the production hall down below, with the support of the organisation's ERP system. During the planning process, the information power lay with the administrative functions and ran smoothly downstream towards the production hall. However, when manufacturing jobs entered the production hall as paper files, details about the development of the jobs became opaque to the administrative functions. During the manufacturing process, the production workers, alone, possessed knowledge about 'what is really going on' (quoting a production worker). These workers could only grant visibility on the status and output of a manufacturing job by logging the data into a digital terminal. They were very aware of their information advantage in these moments, and, in a form of resistance to perceived surveillance, they employed workarounds to veil their processes, actively selecting and managing the information they shared.

Thus, the organisation experienced shifting information asymmetries between the planning and execution functions: During the planning process, information levels adhered to the dominant organisational hierarchy, with information flowing from the planning to the execution functions. During the manufacturing process, however, the production workers held significantly more and accurate information on the current status of the manufacturing jobs than the rest of the organisation. This determined a situational inversion of information advantages and consequently a temporary inversion of the hierarchical set-up (Figure 5). These inverted hierarchies on the shop floor denoted a highly relevant peculiarity of the organisational layer, affecting crossdepartmental collaboration and the emergence of workarounds to channel the required information flows.

As neither system nor process design accounted for the inverted hierarchies and information asymmetries, collaborative actions such as those aimed at communicating feedback from the production team to the engineering office were not possible to perform via the digital solutions provided. Technology (i.e. the ERP system) played the role of the representative and authoriser of the dominant hierarchical set-up. However, the back-flow information process, as designed in the ERP system, hindered cross-functional collaboration. The information flow was disrupted, as the ERP system did not allow production workers to provide feedback to the engineering team when issues arose with technical drawings or other 
Figure 5. Inverted hierarchies on the shop floor

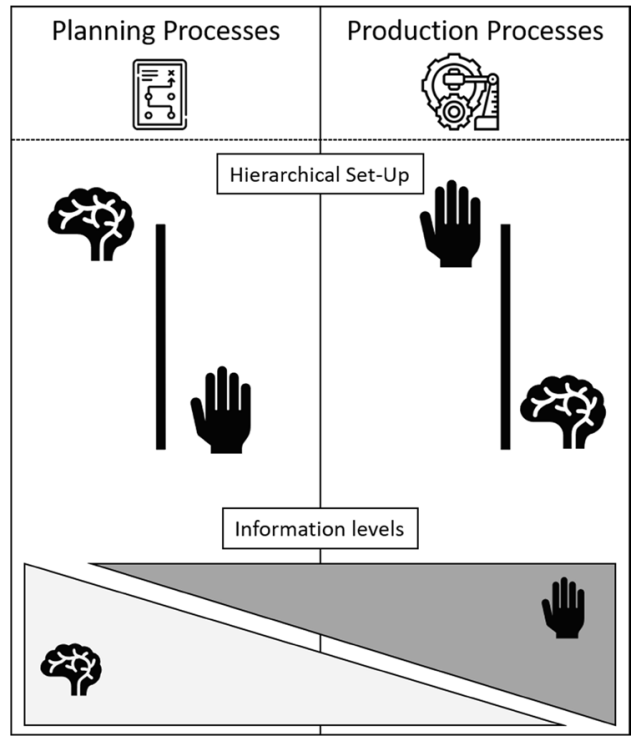

construction-related matters. Furthermore, the workers (more or less) deliberately entered information on manufacturing jobs only partially into the terminals, leveraging notions of control and resistance, as well as temporary power to play on information asymmetries.

Thus, the workarounds can be understood as the result of articulation work, in the sense of Gerson and Star (1986): both the yellow card and the deceptive story about the ill-manufactured part served to meet the local constraints of limited information flows against the hierarchical slope. Constraints, which are addressed more fully in Sect. 5.2, are linked to awareness. More specifically, the workarounds described in this study could be interpreted as 'specialized local shortcuts' (Gerson 2008, p. 198) to raise administrative workers' awareness of constraints encountered during the manufacturing process. In their classic study of London Underground control operators, Heath and Luff (1992) highlighted that awareness decisively supports collaboration through tacit, non-explicit communication (see also Bentley et al. 1992). These early ethnographically informed findings emphasise that awareness is not only relevant for successful collaboration, but it also extends beyond the flow of formal information, and includes careful attention to actions and implicit communication. They also stress that awareness should emerge in the background, so that it does not interfere with primary tasks (Gross 2013, p. 428). At SteelWorks, Inc., an awareness of issues arising during manufacturing might be made manifest and raised via a feedback option in the ERP logging system, once the reluctance of workers to use this system is addressed at an organisational level. Accordingly, the following section addresses how the organisational layer of workarounds might support the practical development of systems design. 
5.2 Implications for CSCW design: Workarounds as signifiers of constraints

Workarounds, or deviations from expected work practices, provide highly relevant information when considered through the organisational layer. Rather than simply indicating deficiencies, workarounds can helpfully reveal system constraints and highlight areas (i.e. processes and practices) that require careful boundary management and configuration at the intersection between analogue, digital, and human agents within the organisational system. The present results have practical implications for CSCW design, building on an understanding of workarounds as signifying: (1) processes of critical relevance for collaboration, (2) areas of mismatch between information and its intended use, and (3) areas that explicitly require a multi-directional informational flow.

First, in their role as signifiers for (sub)processes of critical relevance for collaboration, emergent workarounds highlight procedures considered sufficiently significant that specific practices are enacted to ensure they are maintained. In the present study, the establishment of the yellow card system can be understood as one such workaround with central relevance for organisational functioning. This workaround was established by non-design functions, yet visible to and supported by other teams. Its cross-functional and enduring application demonstrates wide consent amongst employees with respect to its support of the upstream flow of information. Such workarounds have the potential to significantly improve the efficiency of collaboration, and should be considered in a refined requirements analysis in systems design.

Second, workarounds can reveal misalignments between information and its intended use. That is, they may highlight situations in which users perceive the information they are required to provide as incompatible with their understanding of its relevance to the successful completion of a process (i.e. organisational functioning). In the present study, the workaround strategies employed by production workers to impede the exact logging of their set-up time serve as an example of this workaround category. Such workarounds provide valuable information on constraints in the design and boundary management of information at cross-departmental interfaces, and may indicate a need for different framings.

Third, workarounds may signify areas requiring a multi-directional informational flow. In the present study, the underlying constraints originated from shifts in information asymmetries in conjunction with temporary hierarchical inversions. When information flows were triggered in an unintended direction (as in the case of the production worker's catastrophe tale), a message was sent that existing analogue or digital modes of communication were not suitable to communicate vital information. Thus, an exceptional flow of feedback was triggered that disregarded the constraints determined by the organisational set-up.

Given their relevance for organisational functioning, workarounds emphasise the need for more than one best practice of information processing, and therefore 
the need for flexibility in the design of systems and process flows. They uncover the boundaries and restrictions of mapped processes and can facilitate a deeper understanding of organisational constraints relevant to CSCW design.

\subsection{Limitations and future work}

Although the present fieldwork was undertaken at an SME in the production sector, the results should be understood as exploratory in nature, preparing the ground for further ethnographic research. The organisational dynamics of SMEs, in conjunction with the dichotomous structure of the production industry, are distinct from many multinational corporations and complex organisations. Thus, the relationship between hierarchical inversion and the emergence of workarounds in other organisational contexts-especially the knowledge work and healthcare sectors-denotes a relevant field for further research.

The abovementioned research agenda is supported by the present finding that employees at SteelWorks, Inc. did not consider enabling or supporting functions (i.e. human resources, finance, legal) to fall within the hierarchical opposition expressed by oben versus unten. Rather, these functions were considered administrative, yet within a functional space detached from the main hierarchical entanglements. More insight should be gained into whether subtle and/or situational attributions apply to these organisational functions-and, if so, their implications for systems design. Such work would also respond to the call of Monteiro et al. (2013) for more research on CSCW issues related to information infrastructures (e.g. ERP systems) in this context.

\section{Conclusion}

This paper aimed at answering three main research questions: (1) Why do workarounds occur, from an organisational perspective? (2) What role does technology (i.e. an ERP system) play in these situations? and (3) What implications can be derived for CSCW design?

By introducing the organisational layer to the analysis of workarounds, the work showed that information flows in collaborative work environments cannot be regarded as unidirectional. Rather, the findings suggest that, in SMEs in the production sector, the deep-rooted organisational division between planning and execution functions is still at play, but it yields a more complex and dynamic structure associated with situational shifts in information asymmetries and temporary inversions of the hierarchy. Applying the theoretical framework of hierarchical opposition and the inversion of hierarchies (Dumont), the analysis aimed at revealing the mechanisms behind the emergence of workarounds as reactions to organisationally induced situational deficiencies in information flows. In doing so, it sought to address the cause of workarounds, from an organisational 
perspective. In relation to the role of technology in such situations, the results demonstrated that workarounds may signify: (1) processes of critical relevance for collaboration, (2) mismatches between information and its intended use, and (3) areas requiring a multi-directional information flow. The constraints associated with these three dimensions were distilled into practical implications for CSCW design.

The present work adds to the existing body of research on workarounds by contributing an empirical study in the context of CSCW research. The work furthermore exemplifies how ethnographic methods, in conjunction with anthropological theories, may represent a fruitful approach to gain deeper insight into workarounds, in general, and the organisational layer of workarounds, in particular. By documenting and describing the working praxis at SteelWorks, Inc., drawing on ethnographic vignettes, this paper has illustrated how workarounds were applied in that context to foster information processing. Hence, such workarounds were supportive of the company's aim to successfully produce goods. Thus, through its novel analysis of workarounds through an organisational lens, this paper represents an original contribution to the CSCW literature, confirming the value of workarounds as a source of insight into collaborative practices.

\section{Acknowledgements}

I would like to thank the employees of the SME, who allowed me to accompany them through their workday and generously devoted their time (also outside of working hours) to patiently answer my numerous questions. I would also like to thank the Department of Ergonomics at the Technische Universität Berlin, Germany, for providing funding for this study. Finally, many thanks are due to my fellow researchers and Prof. Dr. Markus Feufel from Technische Universität Berlin for their vivid and reflective comments during the data analysis and drafting process of this paper, and particularly Dr. Maren Heibges for her constructive and detailed feedback prior to submission. My thanks also go to the three anonymous reviewers, who provided thoughtful and stimulating feedback on the original manuscript and shaped the paper into its present form.

\section{Funding}

Open Access funding enabled and organized by Projekt DEAL.

Open Access This article is licensed under a Creative Commons Attribution 4.0 International License, which permits use, sharing, adaptation, distribution and reproduction in any medium or format, as long as you give appropriate credit to the original author(s) and the source, provide a link to the Creative Commons licence, and indicate if changes were made. The images or other third party material in this article are included in the article's Creative Commons licence, unless 
indicated otherwise in a credit line to the material. If material is not included in the article's Creative Commons licence and your intended use is not permitted by statutory regulation or exceeds the permitted use, you will need to obtain permission directly from the copyright holder. To view a copy of this licence, visit http://creativecommons.org/licenses/by/4.0/.

\section{References}

Abbott, Kenneth R.; and Sunil K. Sarin (1994). Experiences with Workflow Management: Issues for the Next Generation. In CSCW '94. Proceedings of ACM Conference on Computer Supported Cooperative Work, Chapel Hill, USA, 22-26 October 1994. New York: ACM Press, pp. 113-120. https://doi.org/10.1145/192844.192886

Alter, Steven L. (2014). Theory of workarounds. Communications of the Association for Information Systems (CAIS), vol. 34, art. 55, pp. 1041-1066. https://doi.org/10.17705/1CAIS.03455

Alvarez, Rosio (2008). Examining technology, structure and identity during an enterprise system implementation. Information Systems Journal (ISJ), vol. 18, no. 2, pp. 203-224. https://doi.org/ 10.1111/j.1365-2575.2007.00286.x

Andelfinger, Urs (2002). On the Intertwining of Social and Technical Factors in Software Development Projects. In Y. Dittrich; C. Floyd; and R. Klischewski (eds): Social Thinking: Software Practice. Cambridge: MIT Press, pp. 185-204.

Ash, Joan. S.; Paul. N. Gorman; Mary Lavelle; Thomas H. Payne; Thomas A. Massaro; Gerry L. Frantz; and Jason A. Lyman (2003). A cross-site qualitative study of physician order entry. Journal of the American Medical Informatics Association (JAMIA), vol. 10, no. 2, pp. 188-200. https://doi.org/10.1197/jamia.M770

Avram, Gabriela; Liam Bannon; John Bowers; Anne Sheehan; and Daniel K. Sullivan (2009). Bridging, patching and keeping the work flowing: Defect resolution in distributed software development. Computer Supported Cooperative Work (CSCW), vol. 18, no. 5, art. 477. https:// doi.org/10.1007/s10606-009-9099-6

Bain, Peter; and Phil Taylor (2000). Entrapped by the 'electronic panopticon'? Worker resistance in the call centre. New Technology, Work and Employment, vol. 15, no. 1, pp. 2-18. https://doi.org/10.1111/1468-005X.00061

Barata, João; Paulo Rupino da Cunha; and Luís Abrantes (2015). Dealing with Risks and Workarounds: A Guiding Framework. In J. Ralyté; S. España; and Ó. Pastor (eds): PoEM 2015. The Practice of Enterprise Modeling, Lecture Notes in Business Information Processing, vol. 235. Cham: Springer, pp. 141-155.

Beijsterveld, Joost van; and Willem van Groenendaal (2016). Solving misfits in ERP implementations by SMEs. Information Systems Journal (ISJ), vol. 26, no. 4, pp. 369-393. https://doi. org/10.1111/isj.12090

Bentley, Richard; Tom Rodden; Pete Sawyer; Ian Sommerville; John A. Hughes; Dave Randall; and Daniel G. Shapiro (1992). Ethnographically-informed systems design for air traffic control. In CSCW'92. Proceedings of the Conference on Computer-Supported Cooperative Work, Toronto, Canada, November 1-4, 1992. New York: ACM Press, pp. 123-129. https:// dl.acm.org/doi/10.1145/143457.143470

Bjørn, Pernille; and Nina Boulus-Rødje (2015). The multiple intersecting sites of design in CSCW research. Computer Supported Cooperative Work (CSCW), vol. 24, no. 4, pp. 319351. https://doi.org/10.1007/s10606-015-9227-4 
Blomberg, Jeanette; and Helena Karasti (2013). Reflections on 25 years of ethnography in CSCW. Computer Supported Cooperative Work (CSCW), vol. 22, no. 4, pp. 373-423. https:// doi.org/10.1007/s10606-012-9183-1

Boesen, Julie; Jennifer A. Rode; and Clara Mancini (2010). The Domestic Panopticon: Location Tracking in Families. In UbiComp '10. Proceedings of the 12th ACM International Conference on Ubiquitous Computing, Copenhagen, Denmark, 26-29 September 2010. New York: ACM Press, pp. 65-74.

Button, Graham; David Mason; and Wes Sharrock (2003). Disempowerment and resistance in the print industry? Reactions to surveillance-capable technology. New Technology, Work and Employment, vol. 18, no. 1, pp. 50-61. https://doi.org/10.1111/1468-005X.00110

Choudrie, Jyoti; and Efpraxia D Zamani (2016). Understanding individual user resistance and workarounds of enterprise social networks: The case of Service Ltd. Journal of Information Technology, vol. 31, no. 2, pp. 130-151. https://doi.org/10.1057/jit.2016.9

Courtright, John F.; William H. Acton; Michael L. Frazier; and J. Walter Lane (1988). Effects of "Workarounds" on Perceptions of Problem Importance During Operational Test. In Proceedings of the Human Factors Society $32^{\text {nd }}$ Annual Meeting, vol. 32, no. 17, pp. 1150-1153. https://doi.org/10.1177/154193128803201705

Damon, Frederick H. (2016). The good, the bad, and the dead: The place of destruction in the organization of social life, which means hierarchy. Social Analysis: The International Journal of Social and Cultural Practice, vol. 60, no. 4, pp. 58-75. http://www.jstor.org/stable/ 26404999 [accessed 22.05.2021]

Dumont, Louis (1980[1966]). Homo Hierarchicus: The Caste System and Its Implications. Chicago: University of Chicago Press.

Dumont, Louis (2013[1980]). On value: The Radcliffe-Brown Lecture in Social Anthropology, 1980. HAU: Journal of Ethnographic Theory, vol. 3, no. 1, pp. 287-315. https://doi.org/10. 14318/hau3.1.028

Dupret, Katia (2017). Working around technologies: Invisible professionalism? New Technology, Work and Employment, vol. 32, no. 2, pp. 174-187. https://doi.org/10.1111/ntwe.12093

Ejnefjäll, Thomas; and Pär Ågerfalk (2019). Conceptualizing workarounds: Meanings and manifestations in information systems research. Communications of the Association for Information Systems (CAIS), vol. 45, article 20, pp. 340-363. https://doi.org/10.17705/1CAIS.04520

Emerson, Robert M.; Rachel Fretz; and Linda L. Shaw (2011). Writing Ethnographic Fieldnotes (2nd ed). Chicago: University of Chicago Press.

European Commission (2003). Recommendation of 6 May 2003 concerning the definition of micro, small and medium-sized enterprises (text with EEA relevance) (notified under document number C(2003) 1422). Official Journal of the European Commission L 124, May 2003. https:// eur-lex.europa.eu/eli/reco/2003/361/oj [accessed 9.11.2020]

European Commission (2021). SME Performance Review: Internal Market, Industry, Entrepreneurship and SMEs, European Commission Annual Report. European Innovation Council and SMEs Executive Agency (EISMEA), July 2021. https://ec.europa.eu/docsroom/documents/ 46062 [accessed 23.08.2021]

Ferneley, Elaine H.; and Polly Sobreperez (2006). Resist, comply or workaround? An examination of different facets of user engagement with information systems. European Journal of Information Systems, vol. 15, no. 4, pp. 345-356. http://dx.doi.org/10.1057/palgrave.ejis.3000629

Feuchtwang, Stephan (2016). Civilization, hierarchy, and political-economic inequality. Social Analysis: The International Journal of Social and Cultural Practice, vol. 60, no. 4, pp. 76-95. http://www.jstor.org/stable/26405000 [accessed 22.05.2021]

Foley, Sarah; Nadia Pantidi; and John McCarthy (2019). Care and design: An ethnography of mutual recognition in the context of advanced dementia. In CHI'19. Proceedings of the 2019 
CHI Conference on Human Factors in Computing System, Glasgow, Scotland, UK, 4-9 May 2019. New York: ACM Press, paper 610, pp. 1-15.

Foth, Marcus; Tommi Heikkinen; Johanna Ylipulli; Anna Luusua; Christine Satchell; and Timo Ojala (2014). UbiOpticon: Participatory Surveillance with Urban Screens and Mobile Phone Cameras. In PerDis'14. Proceedings of the International Symposium on Pervasive Displays, Copenhagen, Denmark, 3-4 June 2014. New York: ACM Press, pp. 56-61. https://doi.org/10. $1145 / 2611009.2611034$

Foucault, Michel; translated by A. Sheridan (1995). Discipline \& Punish: The Birth of the Prison. New York: Vintage Books.

Fox, Sarah E.; Kiley Sobel; and Daniela K. Rosner (2019). Managerial Visions: Stories of Upgrading and Maintaining the Public Restroom with IoT. In CHI'19. Proceedings of the 2019 CHI Conference on Human Factors in Computing Systems, Glasgow, Scotland, UK, 4-9 May 2019. New York: ACM Press, paper 493, pp. 1-15.

Gasser, Les (1986). The integration of computing and routine work. ACM Transactions on Office Information Systems, vol. 4, no. 3, pp. 205-225. https://doi.org/10.1145/214427.214429

Gerson, Elihu M.; and Susan Leigh Star (1986). Analyzing due process in the workplace. ACM Transactions on Information Systems, vol. 4, no. 3, pp. 257-270. https://doi.org/10.1145/ 214427.214431

Gerson Elihu M. (2008) Reach, Bracket, and the Limits of Rationalized Coordination: Some Challenges for CSCW. In M. Ackerman; C. Halverson; T. Erickson; and W. A. Kellogg (eds): Resources, Co-Evolution and Artifacts. Computer Supported Cooperative Work. London: Springer, pp. 193-220. https://doi.org/10.1007/978-1-84628-901-9_8

Glaser, Bernard; and Anselm L. Strauss (1967). Discovery of Grounded Theory: Strategies for Qualitative Research. Philadelphia: Aldine Publishing Company.

Grinter, Rebecca E. (2000). Workflow systems: Occasions for success and failure. Computer Supported Cooperative Work (CSCW), vol. 9, no. 2, pp. 189-214. https://doi.org/10.1023/A:10087 19814496

Gross, Tom (2013). Supporting effortless coordination: 25 years of awareness research. Computer Supported Cooperative Work (CSCW), vol. 22, no. 4-6, pp. 425-474.

Hage, Per; Frank Harary; and Bojka Milicic (1995). Hierarchical opposition. Oceania, vol. 65, no. 4, pp. 347-354.

Halbesleben, Jonathon R.; Douglas S. Wakefield; and Bonnie J. Wakefield (2008). Workarounds in health care settings. Health Care Management Review, vol. 33, no. 1, p. 2-12. https://doi.org/10.1097/01.HMR.0000304495.95522.ca

Harrison, Steve; Deborah Tatar; and Phoebe Sengers (2007). The Three Paradigms of HCI. In Alt.Chi. Session at the SIGCHI Conference on Human Factors in Computing Systems, San Jose, California, USA, 28 April-3 May 2007, pp. 1-18.

Haynes, Naomi; and Jason Hickel (2016). Introduction: Hierarchy, value, and the value of hierarchy. Social Analysis, vol. 60, no. 4, pp. 1-20. https://doi.org/10.3167/sa.2016.600401

Heath, Christian; and Paul Luff (1992). Collaboration and control: Crisis management and multimedia technology in London Underground line control rooms. Computer Supported Cooperative Work (CSCW), vol. 1, pp. 69-94. https://doi.org/10.1007/BF00752451

Heibges, Maren; Frauke Mörike; and Markus A. Feufel (2019). Wann braucht Ethnografie eine Einverständniserklärung? Praktische Antworten auf ethische Fragen zu ethnografischen Methoden in der HCI-Forschung. In Mensch und Computer 2019 - Workshopband. Bonn: Gesellschaft für Informatik e.V. https://doi.org/10.18420/muc2019-ws-258-02

Holt, Anatol W. (1988). Diplans: A new language for the study and implementation of coordination. ACM Transactions on Information Systems, vol. 6, no. 2, pp. 109-125. https://doi.org/ $10.1145 / 45941.45942$ 
Houseman, Michael; translated by Eléonore Rimbault (2015). The hierarchical relation: A particular ideology or a general model? HAU: Journal of Ethnographic Theory, vol. 5, no. 1, pp. 251-269. https://doi.org/10.14318/hau5.1.012

Hughes, John A.; Jon O'Brien; Tom Rodden; and Mark Rouncefield (2000). Ethnography, Communication and Support for Design. In P. Luff; J. Hindemarsh: and C. Heath (eds): Workplace Studies: Recovering Work Practice and Informing Systems Design. Cambridge: Cambridge University Press, pp. 187-214.

Hurtienne, Jörn (2017). How cognitive linguistics inspires HCI: Image schemas and imageschematic metaphors. International Journal of Human-Computer Interaction, vol. 33, no. 1, pp. 1-20. https://doi.org/10.1080/10447318.2016.1232227

Hutchins, Edwin (1991). Organizing work by adaptation. Organization Science, vol. 2, no. 1, pp. 14-39. www.jstor.org/stable/2634937 [accessed 22.05.2021].

Iqbal, Rahat; Anne James; and Richard Gatward (2005). Designing with ethnography: An integrative approach to CSCW design. Advanced Engineering Informatics, vol. 19, no. 2, pp. 81-92.

Kapferer, Bruce (2011). Louis Dumont and a Holist Anthropology. In T. Otto; and N. Bubandt (eds): Experiments in Holism: Theory and Practice in Contemporary Anthropology. London: Wiley, pp. 187-208.

Karasti, Helena; and Jeanette Blomberg (2018). Studying infrastructuring ethnographically. Computer Supported Cooperative Work (CSCW), vol. 27, pp. 233-265. https://doi.org/10.1007/ s10606-017-9296-7

Kobayashi, Marina; Susan R. Fussel; Yan Xiao; and Jacob Seagull (2005). Work Coordination, Workflow, and Workarounds in a Medical Context. In CHI EA '05. Extended Abstracts on Human Factors in Computing Systems, Portland, USA, 2-7 April 2005. New York: ACM Press, pp. 1561-1564. https://doi.org/10.1145/1056808.1056966

Lewkowicz, Myriam; and Romain Liron (2019). The missing "turn to practice" in the digital transformation of industry. Computer Supported Cooperative Work (CSCW), vol. 28, pp. 655-683. https://doi.org/10.1007/s10606-019-09347-y

Li, Yizhou; Phillip Haake; and Benjamin Mueller (2017). Explaining the Influence of Workarounds on Effective Use: The Case of a Supply Chain Management System. In Proceedings of the 25th European Conference on Information Systems, Guimarães, Portugal, 5-10 June 2017. https:// aisel.aisnet.org/ecis2017_rp/4 [accessed 9.11.2020]

Light, Ann; and Peter Wright (2009). The Panopticon and the Performance Arena: HCI Reaches Within. In INTERACT 2009. Human-Computer Interaction, Lecture Notes in Computer Science, vol. 5727. Heidelberg: Springer, pp. 201-204.

Lindner, Dominic; and Christian Leyh (2019). Digitalisierung von KMU - Fragestellungen, Handlungsempfehlungen sowie Implikationen für IT-Organisation und IT-Servicemanagement. HMD Praxis der Wirtschaftsinformatik, vol. 56, pp. 402-418.

Ludwig, Thomas; Christoph Kotthaus; Martin Stein; Volkmar Pipek; and Volker Wulf (2018). Revive Old Discussions! Sociotechnical Challenges for Small and Medium Enterprises within Industry 4.0. In ECSCW 2018. Proceedings of 16th European Conference on Computer-Supported Cooperative Work: Exploratory Papers, Nancy, France, 4-8 June 2018. European Society for Socially Embedded Technologies (EUSSET), paper 15. https://dl.eusset.eu/handle/20. $500.12015 / 3116$

Lutters, Wayne G.; and Mark S. Ackerman (2007). Beyond boundary objects: Collaborative reuse in aircraft technical support. Computer Supported Cooperative Work (CSCW), vol. 16, no. 3, pp. 341-372. https://doi.org/10.1007/s10606-006-9036-x

Madden, Raymond (2017). Being Ethnographic: A Guide to the Theory and Practice of Ethnography (2nd ed). London: SAGE. 
McDonald, Seonaidh (2005). Studying actions in context: A qualitative shadowing method for organizational research. Qualitative Research, vol. 5, no. 4, pp. 455-473.

Mentis, Helena M.; Madhu Reddy; and Mary B. Rosson (2010). Invisible Emotion: Information and Interaction in an Emergency Room. In CSCW'10. Proceedings of the 2010 ACM conference on Computer supported cooperative work, Savannah, USA 6-10 February 2010. New York: ACM Press, pp. 311-320. https://doi.org/10.1145/1718918.1718975

Mentis, Helena M.; Reddy, Madhu; and Mary B. Rosson (2013). Concealment of emotion in an emergency room: Expanding design for emotion awareness. Computer Supported Cooperative Work (CSCW), vol. 22, no. 1, pp. 33-63. https://doi.org/10.1007/s10606-012-9174-2

Mörike, Frauke (2016). Working misunderstandings and notions of collaboration: Towards a framework of working misunderstanding as analytical category for ethnographic insight. Civilisations, vol. 65, pp. 145-160. https://doi.org/10.4000/civilisations.4081

Mörike, Frauke (forthcoming). Working Misunderstandings. An Ethnography of Project Collaboration in a Multinational Corporation in India. Bielefeld: transcript.

Monteiro, Eric; Neil Pollock; Ole Hanseth; and Robin Williams (2013). From artefacts to infrastructures. Computer Supported Cooperative Work (CSCW), vol. 22, pp. 575-607. https://doi. org/10.1007/s10606-012-9167-1

Mosko, Mark (1994). Transformations of Dumont: The hierarchical, the sacred, and the profane in India and ancient Hawaii. History and Anthropology, vol. 7, no. 1-4, pp. 19-86. https://doi.org/ 10.1080/02757206.1994.9960840

Mueller, Benjamin; Uta Renken; and Gijs van den Heuvel (2016). Get your act together: An alternative approach to understanding the impact of technology on individual and organizational behavior. ACM SIGMIS Database: The DATABASE for Advances in Information Systems, vol. 47, no. 4, pp. 67-83. https://doi.org/10.1145/3025099.3025107

Orlikowski, Wanda J. (2008). Using Technology and Constituting Structures: A Practice Lens for Studying Technology in Organizations. In M. Ackerman; C. A. Halverson; T. Erickson; and W. A. Kellogg (eds.): Resources, Co-Evolution and Artifacts. Computer Supported Cooperative Work. London: Springer, pp. 255-305. https://doi.org/10.1007/978-1-84628-901-9_10

Pallesen, Trine; and Peter H. Jacobsen (2018). Articulation work from the middle: A study of how technicians mediate users and technology. New Technology, Work and Employment, vol. 22, no. 2, pp. 171-186. https://doi.org/10.1111/ntwe.12113

Parsons, Talcott (1977). Social Systems and the Evolution of Action Theory. New York: Free Press.

Peacock, Vita (2015). The negation of hierarchy and its consequences. Anthropological Theory, vol. 15, no. 1, pp. 3-21. https://doi.org/10.1177/1463499614564887

Pentland, Brian T.; and Henry H. Rueter (1994). Organizational routines as grammars of action. Administrative Science Quarterly, vol. 39, no. 3, pp. 484-510. https://doi.org/10. 2307/2393300

Pollock, Neil (2005). When is a work-around? Conflict and negotiation in computer systems development. Science, Technology, \& Human Values, vol. 30, no. 4, pp. 496-514. https://doi. org/10.1177/0162243905276501

Randall, Dave; Harper, Richard; and Mark Rouncefield (2005). Fieldwork and ethnography: A perspective from CSCW. In Ethnographic Praxis in Industry Conference Proceedings, Redmond, USA, 14-16 November 2005. Arlington: American Anthropological Association, pp. 81-99. https://doi.org/10.1111/j.1559-8918.2005.tb00010.x

Röder, Nina; Michael Schermann; Manuel Wiesche; and Helmut Krcmar (2014). Why Managers Tolerate Workarounds: The Role of Information Systems. In AMICIS 2014. Proceedings of the Twentieth Americas Conference on Information Systems, pp. 1-13.

Rönkkö, Kari; Yvonne Dittrich; and Dave Randall (2005). When plans do not work out: How plans are used in software development projects. Computer Supported Cooperative Work (CSCW), vol. 14, pp. 433-468. https://doi.org/10.1007/s10606-005-9004-x 
Rothmann, Robert (2017). Video surveillance and the right of access: The empirical proof of panoptical asymmetries. Surveillance \& Society, vol. 15, no. 2, pp. 222-238. https://doi.org/ 10.24908/ss.v15i2.6029

Safadi, Hani; and Samer Faraj (2010). The Role of Workarounds During an Opensource Electronic Medical Record System Implementation. In ICIS 2010. Proceedings of the 31st International Conference on Information Systems, paper 47. https://aisel.aisnet.org/icis2010_ submissions/47 [accessed 23.08.2021]

Schmidt, Kjeld (2016). Computer-Supported Cooperative Work (CSCW). In K. Jensen; R. Craig; J. Pooley; and E. W. Rothenbuhler (eds): The International Encyclopedia of Communication Theory and Philosophy. Hoboken: Wiley. https://doi.org/10.1002/9781118766804. wbiect144

Schmidt, Kjeld; and Liam Bannon (2013). Constructing CSCW: The first quarter century. Computer Supported Cooperative Work (CSCW), vol. 22, no. 4, pp. 345-372. https://doi.org/10. 1007/s10606-013-9193-7

Schmidt, Kjeld (2002). Remarks on the complexity of cooperative work. Computer Supported Cooperative Work (CSCW), vol. 16, no. 4-5, pp. 443-483. https://doi.org/10.1007/ 978-1-84800-068-1_9

Schmidt, Kjeld (1997). Of Maps and Scripts: The Status of Formal Constructs in Cooperative Work. In GROUP '97. Proceedings of the ACM Conference on Supporting Group Work Phoenix, USA, 16-19 November 1997. New York: ACM Press, pp. 138-147. https://doi.org/ $10.1145 / 266838.266887$

Schmidt, Kjeld; and Carla Simone (1996). Coordination mechanisms: Towards a conceptual foundation of CSCW systems design. Computer Supported Cooperative Work (CSCW), vol. 5, pp. 155-200. https://doi.org/10.1007/BF00133655

Schmidt, Kjeld; and Liam Bannon (1992). Taking CSCW seriously: Supporting articulation work. Computer Supported Cooperative Work, vol. 1, no. 7, pp. 7-40. https://doi.org/10. 1007/BF00752449

Schorch, Marén; Fabienne Seifert; Hussain A. Syed; Christoph Kotthaus; and Volkmar Pipek (2020). Doing CSCW Research in Small and Medium Enterprises: Experiences, Options and Challenges. In Proceedings of the 18th European Conference on Computer-Supported Cooperative Work, Workshop Papers, Siegen, Germany, 13-17 June 2020. European Society for Socially Embedded Technologies (EUSSET), workshop 2. https://doi.org/10.18420/ecscw 2020_ws02

Schubert, Thomas (2005). Your highness: Vertical positions as perceptual symbols of power. Journal of Personality and Social Psychology, vol. 89, no. 1, pp. 1-21. https://doi.org/10.1037/00223514.89.1.1

Seering, Joseph; Juan P. Flores; Saiph Savage; and Jessica Hammer (2018). The Social Roles of Bots: Evaluating the Impact of Bots on Discussions in Online Communities. Proceedings of the ACM on Human-Computer Interaction, vol. 2, issue CSCW, art. 157. https://doi.org/10.1145/ 3274426

Sia, Siew Kein; May, Tang; Christina Soh; and Wai Fong Boh (2002). Enterprise resource planning (ERP) systems as a technology of power: Empowerment or panoptic control? ACM SIGMIS Database: The DATABASE for Advances in Information Systems, vol. 33, pp. 23-37. https://doi. org/10.1145/504350.504356

Sprenger, Guido (2006). Die Männer, die den Geldbaum fällten: Konzepte von Austausch und Gesellschaft bei den Rmeet von Takheung, Laos. Münster: LIT Verlag.

Star, Susan Leigh; and Anselm Strauss (1999). Layers of silence, arenas of voice: The ecology of visible and invisible work. Computer Supported Cooperative Work (CSCW), vol. 8, no. 1-2, pp. 9-30. https://doi.org/10.1023/A:1008651105359 
Strauss, Anselm L. (1985). Work and the division of labor. The Sociological Quarterly, vol. 26, no. 1, pp. 1-19.

Strong, Diane; and Olga Volkoff (2010). Understanding organization-enterprise system fit: A path to theorizing the information technology artifact. Management Information Systems Quarterly, vol. 34, no. 4, pp. 731-756. https://doi.org/10.2307/25750703

Suchman, Lucy A. (1987). Plans and Situated Actions: The Problem of Human-Machine Communication. Cambridge: Cambridge University Press.

Taylor, Frederick W. (2003). Scientific Management. Abington: Routledge.

Vassilakopoulou, Polyxeni; Miria Grisot; and Margunn Aanestad (2010). Between personal and common: The design of hybrid information spaces. Computer Supported Cooperative Work (CSCW), vol. 28, pp. 1011-1038. https://doi.org/10.1007/s10606-017-9304-y

Veeraraghavan, Rajesh (2013). Dealing with the Digital Panopticon: The Use and Subversion of ICT in an Indian Bureaucracy. In ICTD 2013. Proceedings of the Sixth International Conference on Information and Communication Technologies and Development, Full Papers, Cape Town, South Africa, December 7-10, 2013, vol. 1, pp. 248-255. https://doi.org/10.1145/25166 04.2516631

Zacklad, Manuel (2003). Communities of Action: A Cognitive and Social Approach to the Design of CSCW Systems. In Proceedings of the ACM Conference on Supporting Group Work (GROUP'13), Sanibel Island, USA, 9-12 November 2003. New York: ACM Press, pp. 190-197. https://doi.org/10.1145/958160.958190

Zhou, Xiaomu; Mark Ackerman; and Kai Zheng (2011). CPOE Workarounds, Boundary Objects, and Assemblages. In CHI '11. Proceedings of the SIGCHI Conference on Human Factors in Computing Systems, Vancouver, Canada, 7-11 May 2011. New York: ACM Press, pp. 3353 3362. https://doi.org/10.1145/1978942.1979439

Publisher's Note Springer Nature remains neutral with regard to jurisdictional claims in published maps and institutional affiliations. 